\title{
The Role of Evidence in Chronic Care Decision-Making
}

\author{
Fabrizio Macagno' ${ }^{1} \cdot$ Sarah Bigi ${ }^{2}$
}

(c) Springer Nature B.V. 2020

\begin{abstract}
In the domain of medical science, factual evidence is usually considered as the criterion on which to base decisions and construct hypotheses. Evidence-based medicine is the translation of this approach into the field of patient care, and it means providing only the type of care that is based on evidence that proves its effectiveness and appropriateness. However, while the literature has focused on the types and force of evidence used to establish the recommendation and treatment guidelines, the problem of how evidence is used in doctor-patient interactions to motivate, or refuse, treatment or habit change has been almost completely neglected. In this specific context, characterized by the epistemic unbalance between the interlocutors and a specific conversational goal (making a decision shared by the patient), the scientific categories of evidence are often irrelevant. The goal of this paper is to address this challenge by analyzing the role evidence plays in doctor-patient interactions in diabetes care. After introducing an analytical distinction between the epistemic and the pragmatic aspect of evidence, we will propose a classification of the types and functions of evidence in chronic care communication, and illustrate its possible uses through its application to our corpus of diabetes-care consultations. From our qualitative analyses, it is possible to observe how in this communicative context a crucial role is played by the conflicts of evidence, in which providers correct patients' uses of evidence leading them to using less defeasible levels of evidence.
\end{abstract}

Keywords Evidence $\cdot$ Argumentation $\cdot$ Pragmatics $\cdot$ Probative force $\cdot$ Decision-making $\cdot$ Chronic care communication

\section{Introduction}

Evidence is etymologically defined as "appearance from which inferences may be drawn" (Hickey 2016, p. 38). This definition has two crucial dimensions, a logical and an epistemological one. From a logical perspective, evidence is what grounds a conclusion, the ground of an inference. The epistemological aspect is more complex, as the Latin root evidentia refers to what is clear, manifest, visible, namely what can be verified directly as it is apparent and can be hardly doubtful. Evidence is thus scientific proof, which is

Fabrizio Macagno

fabrizio.macagno@fcsh.unl.pt

http://fabriziomacagno.altervista.org

Sarah Bigi

sarah.bigi@unicatt.it

1 Instituto de Filosofia da Nova (IFILNOVA), Universidade Nova de Lisboa, Edifício I\&D - 4 andar, Avenida de Berna 26, 1069-061 Lisbon, Portugal

2 Facoltà di Scienze Linguistiche e Letterature Straniere, Università Cattolica del Sacro Cuore, Largo Gemelli 1, 20100 Milano, Italy grounded on theoretical systems and methods shared and agreed upon by the scientific community. However, it is also "commonsense evidence," namely what can be observed and is evident from everyday experience (Ziman 1991, p. 9).

These two dimensions of evidence are extremely relevant in the field of medicine, in which they play two crucial roles: establishing the generalizations to be used as guidelines for recommendations, and making joint decisions with the patients. The first type of evidence use has characterized medical science since the 1990s', when the term 'evidencebased medicine' (EBM) was introduced to indicate clinical practice providing the most effective care based on the best available research evidence (Guyatt et al. 1992; Chen et al. 2017). It initially began as a reaction to poor use of scientific literature by clinicians, and then developed into an approach that includes criticism to narrow uses of scientific literature, and the acceptance of patients' values and preferences to complement scientific evidence in the definition of the best treatment. This "golden standard" of medical research, however, does not always inform the day-to-day decisions clinicians need to make in their practice, and can be hardly used in the specific contexts of chronic care communication 
(Djulbegovic and Guyatt 2017), which, focusing on prevention, makes patients' involvement and, more importantly patients' education (McCormack et al. 2017), crucially relevant.

In this communicative setting, evidence has a prominent role (Bensing 2000) that has been almost neglected. While in EBM the types and the levels of evidence are debated, discussed, and deeply investigated, there are no studies addressing what, why and how evidence is used in chronic care consultations. The EBM typologies and uses can be of little help in understanding the evidence use in a context in which the sources of information that matter are not primarily the randomized controlled trials, but symptoms, measurements, and trends, and the interlocutor is not an expert, but a patient who needs to understand the evidence referred to and learn to assess and use it (Bunge et al. 2010).

The goal of this paper is to address this challenge by analyzing the role evidence plays in interactions between patients and doctors in a specific chronic care setting (diabetes care). To this purpose, we first introduce an analytical distinction between the epistemic and the pragmatic aspect of evidence, where the former concerns the probative force, and the latter the dialogical function of its use. We will then propose a classification of the types and functions of evidence in this specific area of chronic care communication, and illustrate its possible uses through its application to our corpus of diabetes-care consultations (Bigi 2014). This twofold analytical proposal can bring to light different strategies of evidence use adopted by healthcare providers and patients to pursue distinct objectives.

\section{Decision-Making in Chronic Care}

One of the distinctive features of chronic care is that chronic conditions can have devastating effects if not monitored and treated, but these effects need time to appear. This means that in many cases these conditions do not immediately threaten patients' lives. Often symptoms are scarce, if not completely absent, which gives patients the impression that they are not ill and do not need any treatment. On the one hand, this requires medical staff to be very effective in their communication of the diagnosis and risks in order to stimulate patients' participation in the management of the disease. On the other hand, it grants all the parties involved a certain amount of time, which is absent, for example, in many acute conditions (for example, appendicitis or a broken bone requires urgent treatment). The availability of time makes it possible to manage decisions in a 'diluted' fashion, e.g. presenting the situation and the options during one encounter and allowing the decision to be made in the following one; or allowing patients to verify that one option is not optimal and leading them to choose a more effective solution having experienced-having collected evidence of-the non-effectiveness of the previously chosen one (Bigi et al. 2019). Especially the second strategy is part of the process of participatory care and patient education that is implied by the Chronic Care Model (Wagner et al. 2001; Coleman et al. 2009), i.e. the approach to chronic care most widely accepted, at least in Western countries.

Participatory care is defined as the propensity to involve patients in treatment decisions, and it is commonly characterized by the following factors: (1) the patients' possibility of choosing between different medical care options, also based on their preferences; (2) the discussion of pros and cons of each choice; and (3) taking patient's preferences into account (Heisler et al. 2002). It is rather undisputed today that the practice of shared or participatory decisionmaking can have beneficial effects on the general outcome of medical consultations, especially those that are aimed at achieving a behavior change from patients (Charles et al. 1997; Elwyn et al. 2000, 2012; Emmons and Rollnick 2001; Entwistle et al. 2004; Taylor 2009; Epstein and Street 2011; Politi and Street 2011; Street et al. 2012). On the contrary, the imposition of treatments without incorporating patients' personal goals "undermines motivation and engagement in treatment and sabotages attempts to improve" clinical parameters (Wolpert and Anderson 2001, p. 996).

From a dialogical perspective, this approach is grounded on the possibility of sharing two types of information. On the one hand, the physician's proposal of possible choices and options, which is based on evidence consisting of patient's clinical data, expert opinions, or the results of research studies or statistics (expertise). Such evidence is fundamental for the doctor's analysis of the possible treatment options, and for informing the patient of possible choices, and the advantages and disadvantages thereof. For this reason, medical evidence needs to be communicated, and more importantly explained, debated over and discussed. On the other hand, decisions cannot be made unless they take into account a second kind of information, consisting of the patient's preferences, symptoms that are not observable through clinical instruments and tests, life conditions, and constraints that can affect a specific behavior or change. Also this type of information needs to be explained, debated, and interpreted, and the grounds and sources thereof discussed (including the specific cases or events occurred, the signs experienced, or the relatives' testimony) (Kuhn 1999).

Evidence is fundamental for making decisions in this context. Decisions, either made together with the doctor or by the patient autonomously, need to be grounded on reasons, and reasons on symptoms accurately interpreted; moreover, possible remedies need to be justified by adequate reference to studies, tests, and authorities (Alston et al. 2012, p. 3). In chronic care, diagnoses, assessments, and decisions need to be evidence-based in the sense of being grounded on data 
from which specific inferences are drawn, meeting a certain standard of proof (Walton 2016, p. 216).

In this perspective, our assumption is that the different types of uses of evidence and the different types of inferences from data to epistemic, evaluative, or deliberative conclusions should be accurately assessed in order to understand the process of sound decision-making. Moreover, based on the educational function of healthcare providers in chronic care consultations (in compliance with the goal of patient empowerment), we assume that one of the possible goals of clinical staff is to teach patients how to assess and use correctly evidence, as the core of patient education and inclusion.

The application of this theoretical classification to a corpus of diabetes care interviews can illustrate its possible uses for detecting the levels of evidence that patients and healthcare providers preferentially use for justifying their conclusions or decisions. Moreover, this application can be used for describing the most common strategies that are used by the healthcare providers in our corpus to train patients in developing evidence-based criteria concerning their own condition.

In the following sections, we will present an argumentative approach to evidence, in which the latter is analyzed within the structure of an argument. This approach leads to drawing a distinction between three levels, namely the level of the argumentative function, the epistemic level, and the dialogical level. The identification of different levels of epistemic use of evidence and dialogical uses thereof will allow us to propose a classification that will be used to conduct a qualitative analysis of patient-provider interactions in a chronic care setting. The results of this analysis will be presented and discussed.

\section{The Argumentative Nature of Evidence Use}

The concept of evidence in science is usually thought of as "data that have been scrutinized by various methods or validation criteria" (Aikenhead 2005, p. 248); such a scrutiny leads to a degree of credibility higher than data (Roberts and Gott 2010; Roberts and Johnson 2015). However, as Aikenhead put it, the application of scientific knowledge to everyday decision-making is problematic, as "most often, canonical scientific knowledge is not directly useable in science-related everyday situations" (Aikenhead 2005, p. 245). The first step in the analysis of evidence use in providerpatient communication consists then in the investigation into what counts as evidence in this type of situation.

The dimensions of evidence that are relevant to this type of communication concern the decision-making process, and in particular the provision of grounds to an evaluation and a proposal that are credible. Specifying the notion of credibility, we can claim that the relevant dimension of evidence is its resistance to possible denials and rebuttals, namely its "probative value." This concept has been clearly expressed by Walton in his analysis of evidence (Walton 2002, p. 16):

[...] the basic idea behind all the legal treatises on evidence was that a proposition can have weight of reasonable acceptance in its favor so that a conclusion can be drawn from it by inference, and then the weight of acceptance is transferred to the conclusion. So, for example, if a witness swears on oath that some person carried out some act, this premise shifts a weight of acceptance or so-called probability to the conclusion that the person cited did carry out the act in question. Such an inference is then seen as having "probative value," meaning that it can be used to prove something. Such an inference can therefore be treated as evidence in favor of accepting a conclusion that is in dispute.

The use of evidence as an instrument for developing knowledge, and more importantly in chronic care, making shared decisions, can be represented in five distinct components (Walton 2016, p. 216):

1. The conclusion to be proved (the proposition claimed to be considered as knowledge);

2. A body of data, used as the basis for drawing inferences from them;

3. The collection of the data relevant to support the conclusion, and the interpretation thereof;

4. The chain of reasoning linking the data to the conclusion;

5. The standard of proof that the reasoning needs to meet.

In this perspective, evidence is constituted by data, which in turn can be supported by other evidence (Feldman 2005), or can consist of basic propositions, namely propositions immediately evident (such as "I see a red object"). Evidence can be thus classified in categories depending on their defeasibility conditions and probative force. Depending on how data are collected, and how they are related to the conclusion, it is possible to identify the defeasibility conditionsor defeaters (Feldman 2005, pp. 112-113), which directly affect the probative force of the use of a piece of evidence.

The five components of evidence can be integrated within the classical Toulmin model of argument (Toulmin 1958). In this model, the conclusion (claim) is distinguished from "the facts we appeal to as a foundation for the claim (data)" (Toulmin 1958, p. 90); data and conclusion are connected through an inference (warrant), a justification that shows how the premise can support the conclusion. Finally, Toulmin introduced a third crucial relevant element, the "backings," namely "assurances" or statements of fact defending 
the acceptability of the warrant (Toulmin 1958, pp. 96-98). Toulmin's model can be reinterpreted and specified further to represent the argumentative uses of evidence. As pointed out by Walton (Walton 2016, pp. 215-216), basic propositions, needing no further support, correspond to the perception of the data through the senses ("I see something that looks like a red car"). The other types of evidence correspond to the inference drawn from basic propositions (such as, "this car is red"), and propositions supported by other evidence or inferences.

In this perspective, Toulmin's Data fails to distinguish the information (the evidence) from its interpretation for the purposes of supporting the Claim. The Data thus need to be distinguished from the evidence that can be represented as a broader category of "Backing" (contrary to McNeill et al. 2006, p. 158). As Brockriede and Ehninger underscore (Brockriede and Ehninger 1960), the relationship between Data and claim is a "movement" guaranteed by a warrant, which, however, needs to be recognized. The information that the speakers are taking into account for supporting a potentially controversial conclusion needs to be distinguished from its argumentative use, namely its presentation (or interpretation) as a premise in a proof-a premise that is relevant to the conclusion (Hitchcock 2006, p. 212). Evidence is thus regarded as different from its argumentative use: to become Data, it needs to be framed as a premise of an argumentative inference (a cause leading to an effect; a sign leading to an explanation, a means leading to an end, etc.) (Freeman 2005; Reed and Rowe 2005). The general structure of the argumentative use of evidence can be represented in the modified representation of Toulmin's structure of argument (Fig. 1) (Mayweg-Paus and Macagno 2016, pp. 122-123): shown below.

The analysis of the Data as the interpretation of the evidence (Backing) relevant to the argumentative purpose (Claim) integrates Walton's components of evidence into the argument structure. The body of data (component no. 2-or Backing) is regarded as the grounds providing support to the conclusion (component no. 1, or Claim) through their interpretation

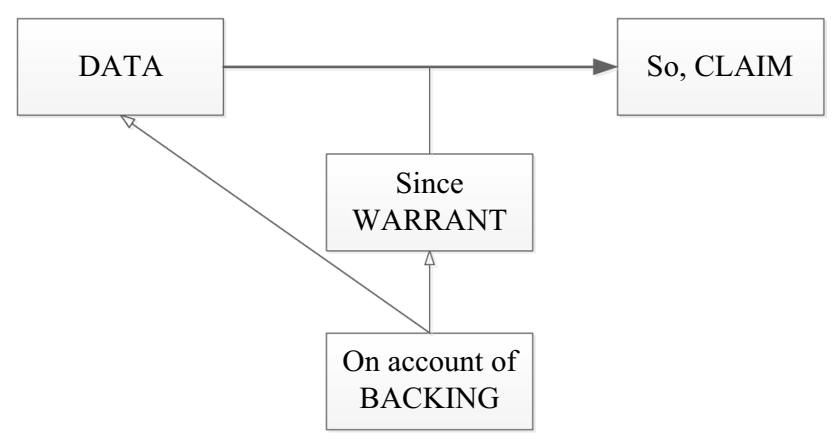

Fig. 1 Argumentative structure of evidence and comparison with other data (component no. 3, or Data) and the inferential step (component no. 4, or Warrant). The relationship between Backing, Data, Warrant, and Conclusion is represented in terms of standard of proof: the more accurate the evidence scrutiny, comparison, and assessment, and the interpretation thereof, the less defeasible the conclusion (Aikenhead 2005; Roberts and Johnson 2015; Walton 2016).

The argument pattern can bring to light another important argumentative aspect of evidence use, namely its level of interpretation. A piece of evidence can be used directly to support a conclusion ("I felt dizzy, so I ate some sugar to prevent hypoglycemia"). Or it can be employed after being interpreted and assessed ("Yesterday I feared to have low levels of glycaemia, as I felt somehow dizzy. Thus, I measured it"). While in the first case evidence is used directly to justify a conclusion, in the second case its function as a backing-and more importantly as a defeasible symptom-is acknowledged. The role of interpretation is crucially related to the argumentative stance towards the evidence. The interpretation of the evidence implies the acknowledgment of its role in the justification of the speaker's conclusion, i.e. its recognition as an "indirect" reason to accept the conclusion, as it does not correspond to the premise on which it is grounded.

These differences between argumentative uses of evidence can be summarized in the following typologies (Dickinson 1998, p. 76; Mayweg-Paus and Macagno 2016, pp. 122-123):

1. First-order evidence: Evidence used to support or challenge a claim directly in an argument (functioning as Toulmin's data).

2. Second-order evidence: Evidence used to support or challenge the validity of how data (first-order evidence) is used to support a claim in an argument (functioning as Toulmin's backing).

The distinction between first-order and second-order evidence highlights the difference between evidence and its use (Gupta and Upshur 2012). Evidence is not identical to a reason, as in order to be used to support a claim, it needs to be interpreted and related to the conclusion that it is intended to lead to. In first-order evidence, this distinction is not considered, and uninterpreted evidence is equated with an argument (Kuhn 2002). This structural distinction can justify the difference between the epistemic levels of evidence use.

\section{The Probative Force Dimension: Levels of Evidence Use}

The notion of interpretation plays a crucial role in medical communication and, more importantly, in patient education. Interpretation concerns the passage from evidence to 
its assessment, and comparison with the possible alternative conclusions that it can support (Walton 2002, pp. 17-18; 42-43). In this perspective, evidence can be considered as an argumentative neutral notion, which after its assessment and interpretation (coordination with a theoretical explanation), can be used for supporting or challenging a conclusion (Kuhn 2002). The assessment of evidence, however, leads to introducing another level of analysis that captures the degrees of probative force of evidence. Evidence is used argumentatively as a defeasible support for a conclusion; however, depending on the defeasibility conditions of this support, the piece of evidence can have different degrees of probative force (Godden and Walton 2006; Walton 2007, chap. 1). The distinction between different levels of evidence depending on their probative force, which we will refer to as "probative force levels" (comparable with the hierarchies of evidence developed in medical literature, see Guyatt and Rennie 2002; Murad et al. 2016) can bring to light some relevant aspects of chronic care communication.

\subsection{Levels of Evidence in Medical Studies}

The different levels of probative force of evidence are crucial in medicine, where the recommendation relies heavily on the evidence that supports both the diagnosis and the intervention. However, medical research has focused primarily on the evidence related to the latter, distinguishing between different types of strength of evidence. The first study that addressed this issue identified four categories ordered based on their reliability, which was then used to rank the types of intervention recommended-for example a recommendation was ranked as A when it was based on good evidence (i.e. level I or in some cases level II evidence) (1979, p. 1195):

I. Evidence obtained from at least one properly randomized controlled trial.

II. Evidence obtained from well-designed cohort or case-control analytic studies, preferably from more than one center or research group.

III. Evidence obtained from comparisons between times or places with or without the intervention.

IV. Opinions of respected authorities, based on clinical experience, descriptive studies or reports of expert committees.

These levels have been modified and refined over the years, starting from (Sackett 1989), and adapted to both the intervention (therapeutic phase) and the diagnosis (for an overview, see Burns et al. 2011), leading to a 5-level scale ordered from the strongest to the least reliable source of evidence (see for instance the guidelines provided for plastic surgery: Evidence-based clinical practice guideline: breast reconstruction with expanders and implants, 2013; these levels are taken for granted in all medical studies, see Sugrue et al. 2019). The common feature of these distinctions and ordering is the principle underlying the assessment of evidence, namely the so-called resistance to certain biases, such as selection bias and observer bias (Upshur 2009, p. 266).

Concerning the first phase, the strongest type of evidence is at present commonly considered to be the one resulting from systematic reviews of randomized control trials or multi-center studies (Level 1), followed by individual randomized control trials or observational studies (Level 2) (Evans 2003; Sugrue et al. 2019), as they are regarded as the least subject to potential bias. The third level of evidence includes systematic review of cohort studies, or individual cohort studies and case control studies, while the least reliable sources of evidence are considered case series with pre/ post test (Level 4) or expert opinion, case studies, or descriptive studies (Level 5).

For the diagnosis phase, the crucial difference lies in the order of the two highest sources of evidence-cohort studies are regarded as stronger than RCT. However, the other levels remain the same. Other studies have then developed hierarchies for determining the accepted types of evidence for other types of clinical questions, such as symptom prevalence or procedures (Miller and Jones-Harris 2005).

\subsection{Types of Evidence Use in Chronic Care Diagnosis}

As mentioned in Sect. 2, decision-making in chronic care is grounded on evidence; however, evidence can be of different types and used in different ways. As commented in the previous section, the hierarchy of types of evidence in the medical context is based on the criterion of reliability and usually refers to the use of evidence for diagnosis.

The use of evidence in interactions in chronic care may take on an additional sense because of the peculiar nature of chronic care (cfr. Sect. 2). In this context, the disease cannot be healed, but patients can be motivated to adopt behaviors-apart from taking medications - that can significantly improve their quality of life and help maintain it over time. This process of patient engagement (Graffigna et al. 2017) has a lot to do with making decisions about patients' lives in a way that patients and their caregivers participate in making them. It is not clear however what specific role evidence takes in this decision-making process.

As underscored in the classical rhetorical tradition, raw facts are not always particularly persuasive; rather, the core of persuasion is the suitability of the facts to the circumstances and the interlocutor's viewpoint (Kinneavy and Eskin 2000, p. 437; Kinneavy 2002). It is facts assessed within a certain context, or against certain goals or values that 'make sense' and can become persuasive. The peculiarity of chronic care is that often patients do not experience annoying symptoms; the evidence of their disease is indirect, 
as for example revealed by a blood test, or by measuring the blood pressure. The risks for a person's health implied by these measurements are less easy to grasp when such values are considered by themselves. What is crucial is the ability to evaluate, to interpret them in the light of a goal, or a context.

Learning how to use the evidence derived from measurements or personal observations to make decisions and evaluations in everyday life is a crucial instrument in view of the goal of patient empowerment and engagement (Bigi 2014, p. 195, 2016, pp. 28-29). However, existing research on argumentation in medical contexts has not specifically addressed how evidence is used or how it can be ordered in the specific context of medical consultations.

To illustrate the distinct types and uses of evidence in chronic care interviews, we will consider some cases drawn from a corpus of transcribed interviews in Italian between diabetes patients and healthcare providers, recorded from March 2012 through March 2014 in the diabetes outpatient clinic of the A.O. I.C.P.-Cusano Milanino, Milan, Italy (Bigi 2014).

In the first example (Case 1), the nurse is explaining to the patient how to behave in certain situations, in which low levels of glycaemia are measured. To this purpose, the nurse is reconstructing the Patient's decision-making reasoning based on a single measurement as an argument. The Patient has observed a low level of glycaemia in his measurements, which in case of diabetes can be highly problematic. To address this issue, he reports to have made immediately the decision to eat something (containing sugar or carbohydrates) to increase the level of glycaemia. In this sense, evidence is used for decision-making; however, the inferential process used is corrected by the Nurse.

\subsubsection{Case 1}

Nurse: In case you happen to find a low value, event that happened to you only once, it is important to understand later on whether you have solved this situation. Surely, once you have seen your glycaemia at the level of 68, you have eaten something.

Patient: Yes, actually I have said, eh

$\mathrm{N}$ : Then, however..

$\mathrm{P}$ : It is not right...

$\mathrm{N}$ : It is important to understand what happened next, as you may have had a high peak of glycaemia. You may have eaten more to compensate this situation, and then the glycaemia has soared.

In this example, the Nurse is reconstructing and correcting the Patient's reasoning, in which the Patient is confronted with a piece of evidence (a 68-glycemic value, as measured through the appropriate instrument), which he uses directly to support the implicit conclusion "I have to eat more to increase the glycaemia" through a specific rule of inference commonly known by patients (sugar increases glycemic values). In the Nurse's reconstruction, confirmed by the Patient, the latter jumps from an observation (evidence) to a decision without any assessment or interpretation thereof. The Patient does not assess the observation, as he does not mention any further measurement or reference to previous trends or normal values. Moreover, he does not indicate any interpretation of the observation (consequence of the failure to assess the observation), as he makes a decision based on general knowledge (need to avoid too low glycemic values) that has not been adapted to the specific episode.

The defeasibility of this use of evidence is challenged by the Nurse, who underscores in the last turn two crucial dimensions of evidence use, namely the possibility of different interpretations, and the defeasibility of a conclusion drawn from a single measurement. The Nurse is challenging the Patient's first-order evidence use, pointing out how the same measurement can lead to different interpretations (low glycemic levels or a temporary low peak), and thus to different decisions (changing eating habits or taking a little sugar to increase the glycaemia). More importantly, the Nurse carries out this type of correction showing how an interpretation based only on a single observation or measurement can be highly defeasible (Macagno and Walton 2014, chap. 7), and how it needs to be confirmed by other evidence.

The distinction between evidence and proof, and between the different probative forces (defeasibility conditions) of evidence are crucial in chronic care communication and patient empowerment. A clear example of the risks of the use of uninterpreted and unassessed evidence is the following, Case 2, in which the Patient is using an observation as a reason for making a decision:

\subsubsection{Case 2}

Patient: Sometimes, when I feel it $<$ the glycaemia $>$ low, I eat honey with...

Nurse: However, also when you feel that it is low, you should check it, as it can be the result of the problem that you have in your ear, which causes dizziness. Therefore, in this case you eat honey, but your glycemia is perfect.

Here, the observation is even less ascertained than in the case above (a feeling not measured through any instrument) and leads to a problematic interpretation (the glycaemia is low) that is used to make a decision (eating honey) that can result in serious problems. The Nurse challenges the first-order evidence use of an observation by showing how it can be explained in different ways (it can be due to low glycemic values or an ear problem) and points out the 
need of resorting to a more sophisticated level of evidence, measurements.

The two cases illustrate three different probative force levels of evidence, namely observations, measured values, and repeated measures (trends). In addition to these three levels, in provider-patient interactions a fourth one is frequently used, namely the comparison between evidence of different health indicators, or body reactions or functions. This probative force level can be illustrated through the following example:

\subsubsection{Case 3}

Nurse: The glycaemia before meals needs to be within 90 and 130; two hours after the meals this level needs to be below 180 . However, up to 180 the glycaemia is within the limits.

Patient: If it is higher, it is not good.

$\mathrm{N}$ : If this is the case, when it happens you should write what you have eaten, so that when you come here, or even at home, you can understand what are the types of food that make it increase.

In this case, the Nurse is explaining how the trend can be used not only for assessing normality and evaluating the patient's health conditions, but also the relationship between types of food and body reactions. Two indicators are taken into account, namely the level of glycaemia and the glycemic content of foods, and by analyzing the impact of the food on the patient's glycaemia trend, it is possible to assess whether a type of food can be eaten and in what quantities. This type of comparison between different indicators can be used also for assessing the patient's specific condition, such as in the following example (Case 4):

\subsubsection{Case 4}

Nurse: Ok, do you bear well a glycemic value of 66 ?

Or does it result in...?

Patient: I feel like eating.

$\mathrm{N}$ : You see, this is a disorder.

P: I feel like eating - and when I stand up I feel a bit of shiver.

$\mathrm{N}$ : You see, this is a symptom.

The overall assessment of the patient's condition is made by comparing the glycemic values with other evidence, in this case observations of physical disorders. The co-occurrence of different pieces of evidence can lead to an assessment of the patient's conditions.

In these examples, illustrative of the evidence uses in the corpus, we can notice some crucial features. First, evidence has an essential argumentative nature in this type of context, as it is used by both the patient and the doctor to support, correct, challenge or explain hypotheses about the patient's condition. In this sense, evidence is used in a process of providing and addressing arguments. Second, this dialogical use of evidence is collaborative, and more specifically educational. One of the crucial goals of diabetes care consultations is to enable patients to understand their disease and assume an active role in its management (Assal et al. 1985; van Dam et al. 2003; Ellis et al. 2004; Collins 2005). Argumentation in this context is thus not between peers, but rather between two differently experienced evidence users, which potentially enables the novice to develop from the expert specific argumentative skills only through engaging in a dialogue (Kuhn 2002; Iordanou et al. 2016; Mayweg-Paus et al. 2016). Third, this evidence is substantially different from the one used for establishing a generalized recommendation or a diagnostic standard to be provided to healthcare providers. At the practice level, the acceptability of these generalizations is hardly questioned. Rather, the problem consists in inferring the patient's condition from medical tests or examinations run by the doctor or the patient, and more importantly the patient's own experience. This type of information can have different degrees of defeasibility depending on its sources (Hitchcock 2006).

\subsection{Levels of Evidence Use in Chronic Care Diagnosis}

In medical care, the assessment of the evidence is normally investigated in terms of "pathways" or strategies of scrutiny, which include the following three crucial typologies (Aikenhead 2005, p. 256):

1. Several measurements. Different measures can become evidence if they collaborate to an inference about what is happening with a patient.

2. A trend in data. Repeated measurements over time (e.g. statistics, common values detected in a span of time, etc.) produce data that form a trend or pattern recognizable to a nurse.

3. Contextual interpretation. An observation is assessed considering the other data and previous trends relative to a specific patient (background knowledge).

These pathways correspond to the evidential passage from specific observations or data to abstractions or statements of fact commonly referred to as the descriptive-theoretical continuum (Latour 1987; Kelly and Takao 2002, pp. 321-322). To these pathways we can add two crucial levels, namely the use of authorities (a crucial level in the clinical evidential hierarchies), and the observation level. The outcome is a scale of evidence based on the different degrees of probative force. 
Table 1 Evidence use-levels of probative force

\begin{tabular}{|c|c|c|}
\hline Probative force of evidence & Description & Example \\
\hline Level 1: Observations & Reporting an observed phenomenon & I feel my glycaemia is low \\
\hline $\begin{array}{l}\text { Level 2: Measured individual } \\
\text { observations }\end{array}$ & $\begin{array}{l}\text { Statements that report individual measurements of } \\
\text { specific qualities, aspects, or events. Measurements } \\
\text { turn specific observations into more objective data }\end{array}$ & My glycaemia was at 68 \\
\hline Level 3: Data collection & $\begin{array}{l}\text { Statements concerning repeated measurements of the } \\
\text { same variable over time. While Level } 2 \text { involves } \\
\text { single measurements, Level } 3 \text { includes a range of } \\
\text { measurements }\end{array}$ & $\begin{array}{l}\text { My glycemic values are usually good, namely on aver- } \\
\text { age. Therefore, the value of } 108 \text { could be a measure- } \\
\text { ment mistake }\end{array}$ \\
\hline $\begin{array}{l}\text { Level 4: Gathering of evidence } \\
\text { from different dimensions of } \\
\text { an issue }\end{array}$ & $\begin{array}{l}\text { Statements gathering measurements, observations, or } \\
\text { given knowledge concerning different aspects of the } \\
\text { problem at issue }\end{array}$ & $\begin{array}{l}\text { The level of your glycated hemoglobin is } 7.8 \text {, which is } \\
\text { still fine. However, your weight increased, and your } \\
\text { eye condition has worsened }\end{array}$ \\
\hline $\begin{array}{l}\text { Level 5: Authorities or scien- } \\
\text { tific studies }\end{array}$ & $\begin{array}{l}\text { Statements expressing relevant results from scientific } \\
\text { studies or authorities in the field }\end{array}$ & $\begin{array}{l}\text { The scientific literature indicates that the glycemic } \\
\text { values should be measured after breakfast } \\
\text { I have read that diabetes can be treated with surgery } \\
\text { Many patients said that generic drugs do not have the } \\
\text { same effects as the original brandname ones }\end{array}$ \\
\hline
\end{tabular}

In Table 1 above, the levels (in part corresponding to the ones detected by Manz and Renga 2017, p. 500; Roberts and Gott 2006, p. 32) are ordered based on the twofold criterion of generalization and defeasibility (McCain 2018, chap. 2). Lower levels (Level 1 and 2) concern individual events, qualities, or occurrences; in contrast, Levels 3-4 involve generalizations resulting from several measurements (Level 3) or a comparison between different data (Level 4). The last level (Level 5) represents the "external" strategy to support a generalization or a factual premise, namely the use of a source that is in position to know or holds specific knowledge.

Within an argumentative perspective, these epistemic levels can be ordered according to their different defeasibility conditions (Walton 2002; Walton and Reed 2008) — which is different from the actual probative force or defeasibility of a specific instance of evidence. This is particularly evident in the case of expert opinion (Level 5). Ideally, this level describes the use of scientific studies, and for this reason it would presuppose a higher level of scrutiny and analysis. However, since external authorities include all types of sources holding specialized or specific knowledge, it can be more defeasible than other types of evidence. Its strength depends on the type of authority chosen. While patients usually have no access to scientific studies, they refer to the opinion of physicians who they consider as experts, or to sources (such as newspapers or magazines) that they deem as scientifically credible. In this case, the problem is the classification of what counts as a good instance of evidence, not the level of evidence used.

The defeasibility of a level of evidence (defeasibility of the transfer of acceptability) needs to be distinguished from the one resulting from its use, namely its interpretation. In this latter case, the relationship between a piece of evidence and the conclusion (namely the interpretation) can be challenged. In the first case, the transfer of acceptability (plausibility) from the evidence to the conclusion can be disputed (Hitchcock 2017, p. 138). Case 1 and Case 2 are clear examples of defeasible interpretation, as in both cases the single measurement or the observation are shown that cannot be used for supporting a conclusion (a decision). Case 4 is an example of showing how the transfer of acceptability can be challenged. The Nurse explains how the single measurement can only weakly support the judgment that the patient is in a problematic condition. This piece of evidence needs to be combined with other evidence in order to reach a stronger conclusion.

\section{The Pragmatic Dimension: Dialogical Purposes of Evidence Use}

In the previous sections, we have analyzed the uses of evidence from an argumentative perspective, showing how evidence uses can differ according to their structure (backing or premise) (Sect. 3) and their probative force (levels) (Sect. 4). However, an argumentative analysis of evidence use cannot be confined to a structural and probative dimension. Arguments support conclusions that can have different dialogical goals, such as making a decision or persuading. The identification of the pragmatic goals of evidence use can bring to light the communicative purposes for which patients and doctors incorporate evidence in their communication, and the purposes that they pursue more frequently. This dimension can integrate the other two, showing not only how they use evidence, but why.

The essentially pragmatic nature of argumentation was underlined by Walton (1990), who underscored how arguments are reasons that can be used for pursuing different dialogical purposes. Instead of defining arguments as purely 


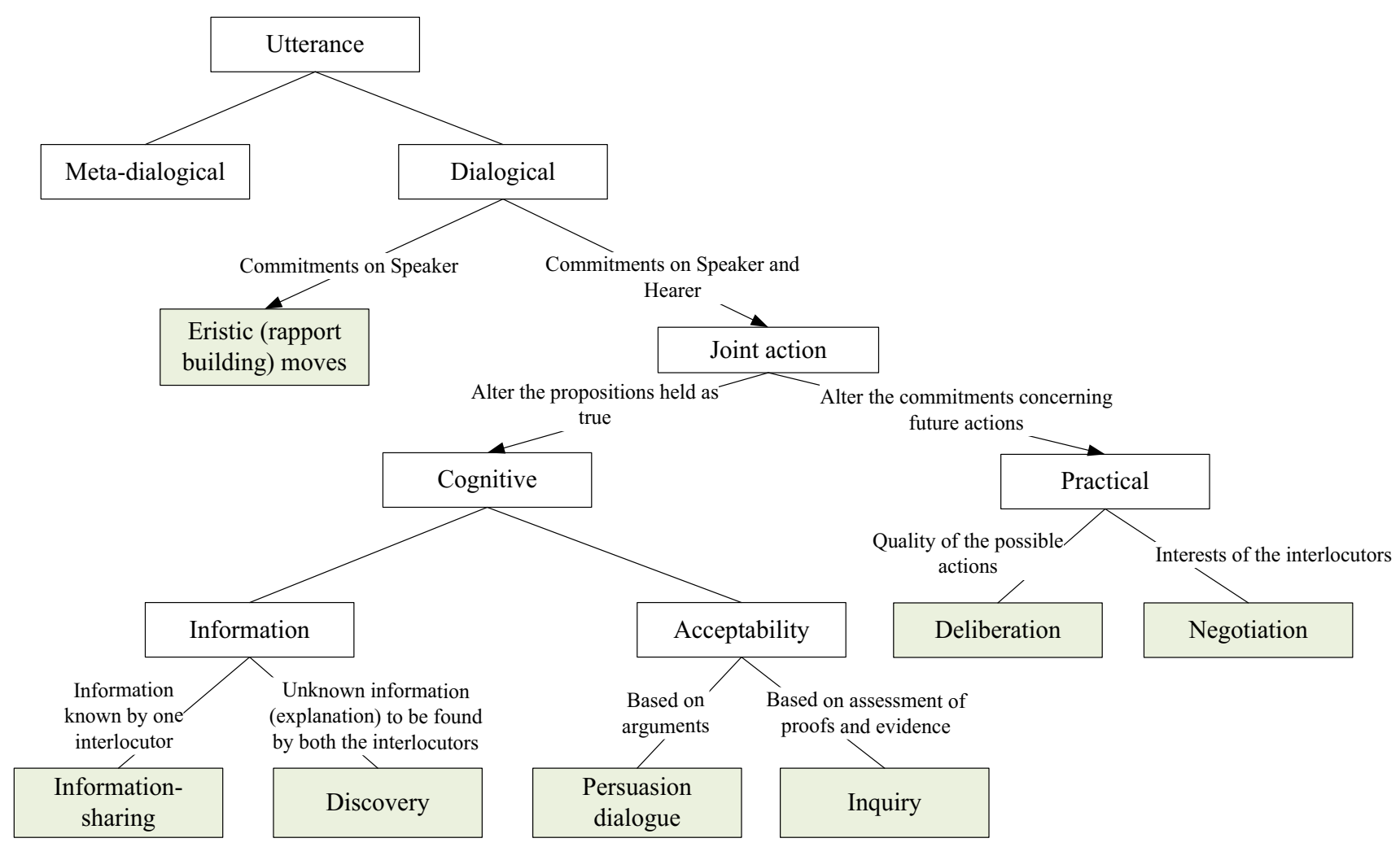

Fig. 2 Dialogical purposes of evidence

logical relations between premises and conclusion, he introduced a pragmatic dimension in his account of argument. In his view, conclusions are moves in a dialogue, which can be of different type. The pragmatic dimension of evidence use can bring to light for what dialogical purposes evidence is used. Analyzing the dialogical functions of evidence corresponds to distinguishing between the most common types of conclusions that evidence can be used to support. For this reason, it is necessary to detect and distinguish between the most general categories of dialogical purposes.

In Macagno and Bigi (2017a, b) and Macagno and Walton (2017), the most general types of dialogue moves were classified according to their dialogical goals, based on the classic theory of the types of dialogue (Walton 1989; Walton and Krabbe 1995). Dialogue moves, representing the basic unit of dialogue, were distinguished and detected according to the dialogical activity that they are intended to propose (for the full procedure and coding scheme for detecting and classifying the moves in chronic care communication, see (Macagno and Bigi 2020). This classification is represented in Fig. 2 above.

This classification can be used for differentiating between the most generic types of evidence use in chronic care consultations. In particular, based on the structure of medical decision-making described in Sect. 2 above, three types of conclusion can need support, namely a decision (deliberation), an evaluation or judgment of a state of affairs (persuasion), and an interpretation of a phenomenon or the explanation thereof (information sharing) (Macagno and Bigi 2020). Case 1 and Case 2 are clear examples of evidence used for making a decision (the patient measures or observes a phenomenon and makes a decision).

An example of the persuasive function is the following Case 5, in which an evaluation of a state of affairs is argued for and against based on arguments:

\subsection{Case 5}

Patient: The glycated hemoglobin seems to be a bit lower, isn't it?

Doctor: No, the glycated hemoglobin is stable.

P: Isn't it lower?

D: No. It is a point higher than the previous one. It has increased instead of decreasing.

P: Eh, but we are still within the acceptable limits.

D: This value needs to decrease. No, this value is not acceptable, and it has not been acceptable for a while.

In this interaction, both the Patient and the Doctor assess the value of glycated hemoglobin as increasing or decreasing, and as acceptable or not. The doctor challenges the patient's evaluation and corrects it based on the values of the glycated hemoglobin reported by the patient. 
The evaluation can be also used as conclusion that is then used for making a decision. The two interrelated dialogical purposes of evidence use can be illustrated in the following example (Case 6), in which two moves (decision making and evaluation) are grounded on the analysis of evidence of different parameters:

\subsection{Case 6}

Doctor: I would say that, given the absence of plaques, the kind of therapy, the absence of cardiopathy, cerebral vasculopathy or familiarity, this condition can be treated just by correcting your diet, also because your parameters are just a little above normal.

Here the Doctor expresses an evaluation on the overall condition of the patient (just above normal) based on a Level 4 evidence. This evaluation (a kind of persuasion move) is used to address a potentially doubtful issue on which the patient may have discordant views (he may be worried or overestimating his condition). This grounded evaluation justifies the proposal (a deliberation move).

The information-sharing function can be divided in two broad categories, namely (1) the explanation of the use of evidence to assess a phenomenon, and (2) the explanation of the passage from a type of evidence to another. In both cases, this function is meta-argumentative, in the sense that it is instrumental for argumentative purposes. Evidence use is explained, and explanations thereof are requested for making decisions or evaluations. An example of the first type of explanation is Case 3. Here, the Nurse explains to the patient the rationale of her evaluation of the glycemic values of the patient.

The second type of explanation consists in the integration of lower level evidence into higher level one. The healthcare provider explains how to use higher level evidence, showing how the level of evidence the patient is relying on is insufficient or highly defeasible. A clear case is the following Case 7 , in which during a discussion concerning the overall situation of the patient, who performs her self-monitoring only sporadically (thus actually relying only on level 2 evidence, single measured observation), the doctor suggests passing to level 3 and then level 4 evidence, which she explains in detail. In this example, the patient already knows the procedure of acquiring evidence of trends and other conditionsthis is only a control visit to a patient who knows already the diary-keeping process. The goal of the doctor is to explain why it is important to follow the procedure:

\subsection{Case 7}

Doctor: It is important to have the pairs [a measurement before meals and another two hours after the same meal], because this way I can see how the medicine is working before and after my meal. And if you make a note for yourself in the diary and you write a high value but next to it also the fact that you had ice cream that day, it takes on a completely different meaning than just looking at numbers. The more interpretation data we have, the better we function.

An analogous use is represented by Case 4, in which the evaluation of a low glycemic value is explained to depend on other elements, such as symptoms. In this case, the Nurse is explaining how to integrate measurements with observations (used as symptoms to make provisional evaluative conclusions), namely the passage from a Level 2 of evidence (measurement) to a Level 4 (comparison between different evidence).

In addition to the category of explanation, other moves that fall into the category of information sharing are the request and provision of evidence that is used later for making an evaluation or decision. An example is the following Case 8:

\subsection{Case 8}

Nurse: How is the blood pressure that you measure at home?

Patient: The minimum is 76 .

$\mathrm{N}$ : The minimum value is very good. The problem is rather the higher one. How is it when you measure it at home? When you measure it, how is it?

In this example, the measures are requested and provided for the purpose of providing an evaluation, which is then discussed.

\section{Trends of the Exploratory Analysis}

From the classification of the dialogue moves and the distinction between the levels of evidence, some observations could be drawn, which can outline some possible trends and point out some possible lines of research. The most evident difference that we detected between the uses of evidence in the two populations is the overall frequency of evidence use. Healthcare providers used evidence in a significantly higher number of cases than patients, as evidence represented $16.6 \%$ of providers' total moves, while only $6.5 \%$ of patients'.

All the probative force levels of evidence use are employed by both patients and healthcare providers. However, the probative force levels were not equally distributed between doctors and patients. While patients and healthcare providers were observed to use all the 5 levels of evidence in their interactions, the frequency of the use is different. We outlined our observations as follows (Table 2): 
Table 2 Probative force levels-distributions (percentages)

\begin{tabular}{llllll}
\hline Role & \multicolumn{3}{l}{ Evidence level } \\
\cline { 2 - 5 } & $\begin{array}{l}\text { Evidence } \\
\text { level 1 } \\
(\%)\end{array}$ & $\begin{array}{l}\text { Evidence } \\
\text { level 2 } \\
(\%)\end{array}$ & $\begin{array}{l}\text { Evidence } \\
\text { level 3 } \\
(\%)\end{array}$ & $\begin{array}{l}\text { Evidence } \\
\text { level 4 } \\
(\%)\end{array}$ & $\begin{array}{l}\text { Evidence } \\
\text { level 5 } \\
(\%)\end{array}$ \\
\hline $\begin{array}{l}\text { Health- } \\
\text { care } \\
\begin{array}{l}\text { Provid- } \\
\text { ers }\end{array}\end{array}$ & 10 & 14 & 54 & 17 & 5 \\
Patients & 38 & 19 & 37 & 7 & 6 \\
\hline
\end{tabular}

While doctors tend to use more level 3 (representing 54\% of the total) and level 4 (17\%) evidence, the levels of evidence used more by patients in a significant way is level 1 (38\%) and level 2 (19\%). Both doctors and patients tend to use little evidence from experts or authorities (5-6\%). The use of different probative force levels of evidence by the participants in the interaction is predictable up to a certain point. Indeed, it is likely that the majority of patients, who are not clinicians themselves, will have more difficulties establishing relations between different measured variables (level 4 evidence) or accessing authorities or addressing the opinion of specialists (level 5 evidence). However, the distribution of these epistemic levels can be combined with the dialogical classification of the uses of evidence and lead to some trends for the quantitative analysis.

The distribution of the dialogical purposes of evidence use also revealed a difference between providers and patients. We distinguished between seven types of dialogical purposes of evidence use, ${ }^{1}$ and the distribution observed was at the top of the next column (Table 3).

The most frequent pragmatic use of evidence in healthcare providers is explanation of evidence use $(31 \%$, significantly different from patients' use, followed by evaluation (26\%) and explanations of the passage from one type of evidence to another (evidence shift) (16\%). Together, the explanations of uses of evidence (both considering the explanation of the individual evidence level and the passage from a level to another) represent almost half of the dialogical goals pursued by the healthcare providers through their use of evidence ( $47 \%$, significantly different from patients' use). The educational role of healthcare providers' evidence uses is even more evident if we consider that the requests of evaluation $(11 \%)$ and explanation (4\%) made by providers are aimed at assessing and potentially correcting the patients' evaluations or understanding of evidence. Overall, the uses of evidence for educational purposes amounts to $62 \%$.

\footnotetext{
${ }^{1}$ We considered only the relationship between the evidence and its immediate purpose. For example, in case of turns characterized by two moves (such as case 6 above), evidence is used primarily for supporting an evaluation, and indirectly for justifying a decision. We code this evidence under the category of an evaluation move.
}

Table 3 Dialogical purposes-distributions (percentages)

\begin{tabular}{llllllll}
\hline Role & \multicolumn{3}{l}{ Purpose } & & & & \\
\cline { 2 - 7 } & $\begin{array}{l}\text { Decision } \\
(\%)\end{array}$ & $\begin{array}{l}\text { Eval } \\
(\%)\end{array}$ & $\begin{array}{l}\text { Eval. } \\
\text { request } \\
(\%)\end{array}$ & $\begin{array}{l}\text { Expl (\%) } \\
\text { Expl. } \\
\text { request } \\
(\%)\end{array}$ & $\begin{array}{l}\text { Expl. of } \\
\text { evidence } \\
\text { shift }(\%)\end{array}$ & $\begin{array}{l}\text { Meas- } \\
\text { ure } \\
(\%)\end{array}$ \\
\hline $\begin{array}{l}\text { Healthcare providers } \\
\text { Patients }\end{array}$ & 9 & 26 & 11 & 31 & 4 & 16 & 4 \\
\hline
\end{tabular}

These percentages were observed to be reversed in the patient population. The majority of the uses of evidence is aimed at assessing a condition or an observation $(61 \%)$ or making a decision (10\%). The requests of evaluations (6\%) or explanations (3\%) are genuine moves of information seeking, like the moves intended to explain how a specific piece of evidence has been interpreted or used (10\%).

The percentages and the frequencies of distribution of types of evidence use show how healthcare providers tend to use evidence mostly for instructing the patients on how to interpret or use evidence for making judgments and decisions. On the contrary, patients tend to use evidence mostly for evaluating their conditions and making decisions, engaging relatively much less in the activity of acquiring knowledge on how to use evidence or integrate it to reach less defeasible assessments.

\section{Argumentative Uses and Conflicts of Probative Forces}

The distinction between the levels of evidence and the dialogical uses thereof highlights the crucial role of explanations in doctors' uses of evidence. This aspect leads to the need of analyzing qualitatively the types and the structures of such explanations. Evidence is explained for two main purposes, namely (1) correcting an interpretation or evaluation of evidence, or a decision based thereon, or (2) showing how to use or interpret evidence, based on requests or on the need of a correction (Macagno and Bigi 2017b).

Evidence is used for purely corrective purposes when it is advanced to challenge a conclusion drawn from the interlocutor. An example is Case 5 above, which is reported again below:

Patient: The glycated hemoglobin seems to be a bit lower, isn't it?

Doctor: No, the glycated hemoglobin is stable.

P: Isn't it lower?

D: No. It is a point higher than the previous one. It is increased instead of decreasing. 
P: Eh, but we are still within the acceptable limits.

D: This value needs to decrease. No, this value is not acceptable, and it has not been acceptable for a while.

Here, the doctor uses the same evidence that the patient is relying on for assessing his own value of glycated hemoglobin and rejects the patient's evaluation. In this case, no further explanation is provided, as the doctor relies on facts or knowledge that he considers as undisputable but fails to explain to the patient the criteria for making a better evaluation. This type of interaction is a rare case in the overall corpus, as healthcare providers tend to explain why an interpretation or in general a conclusion cannot be drawn or is highly defeasible, instead of simply rejecting it.

The most typical cases of explanation fall in the second type, namely replies to requests or reactions to incorrect conclusions or assessments. However, as the figures above show, requests represent a low percentage of the overall evidence moves. The prototypical cases of explanations can be thus considered the explanatory reactions to judgments or decisions based on uninterpreted evidence, or incorrectly assessed or used evidence.

While patients tend to justify choices and decisions based on observations or single measures, clinicians and nurses respond differently to the same kind of evidence. Typically, they start asking questions that might explain whether the parameter could be an isolated case or the symptom of a condition that is worsening, or the causes of the unacceptable parameter, in order to understand if there is need for a change in therapy, or just a different behavior on the part of the patient. Clinicians and nurses tend to respond to these types of evidence uses by patients with moves that introduce the need of moving towards higher evidence levels, namely level 2, 3 or 4 . In other words, they respond by proposing to measure the symptoms, to collect data in a structured way, or to compare measurements of different variables.

The strategies that providers commonly use are two, namely the correction of incorrectly collected evidence, and the integration of lower levels of evidence in higher level ones, which are described and explained. The first strategy consists in the explanation of the correct uses of evidence, or the explanation of the defeasibility of the conclusions drawn from evidence incorrectly collected, combined with explanations of the correct procedures for measuring or comparing data. An example is the following one, in which the nurse is addressing an evaluation of the patient, based on insufficient evidence:

\subsection{Case 9}

Nurse: If you allow me, I repeat that the last glycemia that I can see, which was collected two hours after lunch, is dated 21 May, and the one before it is dated
16 October 2012. Then, on what basis can we say that your glycemia is good? [...]

Patient: My glycemia has never been higher than 200 .

$\mathrm{N}$ : But how can we know it, as you are not doing any self-monitoring?

P: I have measured it every year.

$\mathrm{N}$ : Yes, but in the past your glycated hemoglobulin may have been lower, and then you may have had no low glycemia levels.

In this interaction, the nurse is correcting the incorrect use of evidence of the patient (the value he is relying on is too old and isolated) and explains how it is defeasible. This type of strategy is often combined with an explanation of how to make a correct self-monitoring.

The second strategy can be labeled as conflict of probative force levels of evidence, namely the strategy of addressing a conclusion based on a lower level of evidence through considerations based on higher levels of evidence. This contrast can be expressed as an explicit explanation of how a lower level piece of evidence needs to be integrated into a higher level one, or a correction of a judgment or decision based on evidence of a higher level. In all these cases, the healthcare provider either explicitly or implicitly attacks the evidence that the patient used without assessing and interpreting and shows how a judgment or decision should be supported without incurring the risk of being easily defeated.

An example of a conflict of evidence is the aforementioned Case 7, which is reported below. The doctor addresses a patient who is collecting evidence sporadically:

Doctor: It is important to have the pairs [a measurement before meals and another two hours after the same meal], because in this way I can see how the medicine is working before and after my meal. And if you make a note for yourself in the diary and you report a high value but next to it also the fact that you had ice cream that day, it takes on a completely different meaning than just looking at numbers. The more interpretation data we have, the better we function.

In this case, the doctor explains the patient how to make judgments based on level 3 evidence, instead of level 2, and then he shows how to use level 3 evidence to integrate and compare other evidence, such as reactions to the glycemic value of food, at a higher level (level 4). A similar example is Case 3, in which the nurse explains the maximum and minimum values of glycaemia (level 2) needed for making a judgment, and then she explains how the judgment needs to be integrated within a comparison between different types of evidence (level 4). In particular, she explains how the measurements need to be integrated with the indication of the type of food that resulted in bad values. 
A conflict of evidence can be also expressed as a discussion of an evaluation. For example, in Case 4 above the nurse is addressing the case of a low glycemic value (level 2 evidence), which is immediately judged negatively by the patient. She problematizes the relationship between evidence and evaluation, and leads the patient to considering evidence of other variables that can affect this judgment:

Nurse: Ok, do you bear well a glycemic value of 66 ?

Or does it result in...?

Patient: I feel like eating.

$\mathrm{N}$ : You see, this is a disorder.

P: I feel like eating - and when I stand up I feel a bit of shiver.

$\mathrm{N}$ : You see, this is a symptom.

The nurse is here leading the patient to interpret the level 2 evidence and consider the defeasibility of an evaluation based only on it, suggesting a passage from level 2 to level 4 evidence.

An example of the contrast of evidence for explicitly explaining how a deliberative conclusion should be reached is the following:

\subsection{Case 10}

Nurse: However, unless you check your glycemia in the way that I told you, we cannot understand, as I told you before. Maybe you start off very well, with a low level of glycemia, but what happens after breakfast? Today we realized that you exceeded 200 . Therefore, I need a more reasoned self-monitoring.

Patient: So, in this case, I cannot have my Kellogg's any more.

$\mathrm{N}$ : Let's check first, one measurement is not enough. You can do some experiments, have your regular breakfast one day and the next have something different and see what happens to your glycemia.

The patient is using a level 2 evidence (the level of glycemia measured on a single, specific day) to make a decision (not eating Kellogg's anymore). This type of decision is grounded on an argumentative use of evidence that we described in Sect. 3 as uninterpreted backing, as the evidence is not interpreted and assessed, but used directly to support a conclusion. The nurse is not challenging the conclusion directly, but rather explains how to interpret the level 2 evidence. She points out how a single measurement cannot lead to an evaluation of the patient's reaction to Kellogg's and explains how this judgment needs to be instead based on repeated measurements that can show an overall trend of reactions (level 3 evidence).
This example is similar to Case 1, in which the decision of eating something after detecting low glycemic values (level 2 evidence) is corrected by explaining how the evaluation and the corresponding decision can be highly defeasible (the Nurse says that "as you may have had a high peak of glycaemia. You may have eaten more to compensate this situation, and then the glycaemia has soared"). She then explains that the measured value needs to be compared with other values (level 3 evidence) in order to reach a sounder evaluation.

The correction of the uninterpreted evidence used for making a decision is the target also of the conflicting evidence used in Case 1:

Patient: Sometimes, when I feel it $<$ the glycaemia $>$ low, I eat honey.

Nurse: However, also when you feel that it is low, you should check it, as it can be the result of the problem that you have in your ear, which causes dizziness. Therefore, in this case you eat honey, but your glycemia is perfect

Here, the patient uses an unmeasured observation (level 1) that is used for making a judgment (the glycemia is in danger zone) and then a decision (I eat honey). This conclusion is rejected by the explanation of its defeasibility conditions, and the explanation of the passage to level 2 evidence (measurements).

\section{Discussion and Limitations}

The analyses conducted were purely exploratory and based on the two theoretical classifications presented. This application had three major purposes, namely justifying the choice of the typical instances of evidence use discussed in Sect. 7, showing how these theoretical proposals can be used for empirical purposes, and highlighting some possible trends that can be used as research questions to be explored quantitatively. In particular, this study can justify the development of this twofold categorization in a coding scheme that once validated can be used for quantitative analyses.

The descriptive study of the evidence used in the corpus brought to light two aspects of the interactions that can be considered as relevant in the context of healthcare communication. The first regards high frequency of patients' evaluative uses of evidence. Patients tend to ground their evaluations based on level 1 (55\%), level 3 (27\%) and level $2(12 \%)$ evidence. If we look into the reasons of such evaluations, we can notice that they are provided for justificatory reasons. Patients seem to be preoccupied with providing accounts for behaviors that might 
have caused their parameters to be not good. The patients in our corpus have all had diabetes for many years, so they know very well how the disease functions and what they should be doing to keep it under control. Therefore, this preoccupation with justifying their behaviors is understandable. However, it can also provide a clue as to what kind of arguments could be more effective in this kind of context for achieving behavior change: probably not the ones constructed around higher level evidence, which does not seem to be these patients' first preoccupation.

The second consideration regards clinicians' responses in the same situation. As mentioned above, in most cases clinicians tend to respond to evaluations based on lower levels of evidence with moves that introduce the usefulness of moving towards level 3 or 4 evidence. This behavior suggests that a relevant part of patient education could be considered, in this perspective, in clinicians proposing to patients the passage from the lower, more defeasible, levels of evidence, to the higher and stronger ones.

\section{Conclusions}

Evidence-based medicine has evolved into precision medicine in trying to provide the most specific kind of care to every patient, tailored on their specific needs and characteristics. This includes taking into close consideration patients' lifestyles, habits and general life conditions, which presupposes adopting an inclusive and participatory style of care. Within this framework, patients are led to be more and more autonomous and able to cope with acute episodes and adverse situations, in order to keep their conditions under control in the long term. This effort of patient education implies that patients are also led to understanding how to assess and interpret the symptoms they feel or observe through specific measurements that amount to a kind of evidence.

In our paper, we explored the idea of evidence and the notion of "types" of evidence, pointing out how evidence can be defined from an argumentative perspective as a backing for an implicit or explicit conclusion. This definition results in a twofold analysis of evidence, corresponding to dimensions of support to a conclusion and dialogical purpose. We classified the former dimension outlining the different levels of probative force of evidence use. We then combined a top-down approach to the dialogical purposes of evidence use, based on the types of dialogical moves, with a bottom-up selection of the most frequent moves (also considering the existing literature on the topic of the decision-making process in chronic care). This theoretical approach was then applied to our corpus, to show how it can be used for practical and empirical purposes, and for justifying our qualitative discussion of the most typical cases of evidence uses.

Our analysis showed different uses of evidence from clinicians and patients and also different ways of responding to evidence. In particular, the strategy of conflicts of evidence was shown to be a commonly used way for correcting patients' uses of evidence and leading them to using less defeasible levels of evidence. This preliminary exploration suggests that a larger and more in-depth analysis would be worthwhile to identify specific patterns of evidence use.

Acknowledgements Fabrizio Macagno would like to thank the Fundação para a Ciência e a Tecnologia for the research Grant No. PTDC/FER-FIL/28278/2017

Author Contributions FM is responsible for study conception and design, analysis and interpretation, and drafting of manuscript. SB is responsible for study conception and design, acquisition of data, analysis and interpretation, drafting of par. 2, 4.2, 7, and critical revision of manuscript.

Funding This study was funded by the Fundação para a Ciência e a Tecnologia, research Grant No. PTDC/FER-FIL/28278/2017.

\section{Compliance with Ethical Standards}

Conflict of interest Fabrizio Macagno declares that he has no conflict of interest. Sarah Bigi declares that she has no conflict of interest.

Informed Consent Informed consent was obtained from all individual participants included in the study. All staff and patients provided informed consent and the data collection was approved by the Ethical Committee of the health care facility).

\section{References}

Aikenhead G (2005) Science-based occupations and the science curriculum: concepts of evidence. Sci Educ 89:242-275. https://doi. org/10.1002/sce.20046

Alston C, Paget L, Halvorson G et al (2012) Communicating with patients on health care evidence. Institute of Medicine of the National Academies, Washington

ASPS (2013) Evidence-based clinical practice guideline: breast reconstruction with expanders and implants. ASPS, Arlington Heights

Assal J-P, Mühlhauser I, Pernet A et al (1985) Patient education as the basis for diabetes care in clinical practice and research. Diabetologia 28:602-613. https://doi.org/10.1007/BF00281995

Bensing J (2000) Bridging the gap. The separate worlds of evidencebased medicine and patient-centered medicine. Patient Educ Couns 39:17-25. https://doi.org/10.1016/S0738-3991(99)00087-7

Bigi S (2014) Healthy reasoning: The role of effective argumentation for enhancing elderly patients' self-management abilities in chronic care. In: Riva G, Marsan PA, Grassi C (eds) Active ageing and healthy living: a human centered approach in research and innovation as source of quality of life. IOS Press, Amsterdam, pp 193-203 
Bigi S (2016) Communicating (with) care. A linguistic approach to the study of interactions in chronic care settings. IOS Press, Amsterdam

Bigi S, Sigen T, Piccinini C (2019) Understanding the role of argumentation in chronic care encounters: A comparative analysis of a multicultural corpus. In: Garssen B, Godden D, Mitchell G, Wagemans J (eds) Proceedings of the 9th ISSA Conference. Amsterdam 2018. Sic Sat, Amsterdam, pp 72-79

Brockriede W, Ehninger D (1960) Toulmin on argument: an interpretation and application. Q J Speech 46:44-53. https://doi. org $/ 10.1080 / 00335636009382390$

Bunge M, Mühlhauser I, Steckelberg A (2010) What constitutes evidence-based patient information? Overview of discussed criteria. Patient Educ Couns 78:316-328. https://doi.org/10.1016/j. pec.2009.10.029

Burns P, Rohrich R, Chung K (2011) The levels of evidence and their role in evidence-based medicine. Plast Reconstr Surg 128:305310. https://doi.org/10.1097/PRS.0b013e318219c171

Charles C, Gafni A, Whelan T (1997) Shared decision-making in the medical encounter: what does it mean? (Or it takes, at least two to tango). Soc Sci Med 44:681-692. https://doi.org/10.1016/S0277 -9536(96)00221-3

Chen C-Y, Huang T-W, Kuo KN, Tam K-W (2017) Evidence-based health care: a roadmap for knowledge translation. J Chin Med Assoc 80:747-749. https://doi.org/10.1016/j.jcma.2017.04.010

Coleman K, Austin BT, Brach C, Wagner E (2009) Evidence on the chronic care model in the new millennium. Health Aff 28:75-85. https://doi.org/10.1377/hlthaff.28.1.75

Collins S (2005) Explanations in consultations: the combined effectiveness of doctors' and nurses' communication with patients. Med Educ 39:785-796. https://doi.org/10.111 1/j.1365-2929.2005.02222.x

Dickinson H (1998) Evidence-based decision-making: an argumentative approach. Int J Med Inform 51:71-81. https://doi.org/10.1016/ S1386-5056(98)00105-1

Djulbegovic B, Guyatt GH (2017) Progress in evidence-based medicine: a quarter century on. Lancet 390:415-423. https://doi. org/10.1016/S0140-6736(16)31592-6

Ellis S, Speroff T, Dittus R et al (2004) Diabetes patient education: a meta-analysis and meta-regression. Patient Educ Couns 52:97105. https://doi.org/10.1016/S0738-3991(03)00016-8

Elwyn G, Edwards A, Kinnersley P, Grol R (2000) Shared decision making and the concept of equipoise: the competences of involving patients in healthcare choices. Br J Gen Pract 50:892-899. https://doi.org/10.1007/BF02602306

Elwyn G, Frosch D, Thomson R et al (2012) Shared decision making: a model for clinical practice. J Gen Intern Med 27:1361-1367. https://doi.org/10.1007/s11606-012-2077-6

Emmons K, Rollnick S (2001) Motivational interviewing in health care settings. Opportunities and limitations. Am J Prev Med 20:68-74. https://doi.org/10.1016/s0749-3797(00)00254-3

Entwistle VA, Watt IS, Gilhooly K et al (2004) Assessing patients' participation and quality of decision-making: Insights from a study of routine practice in diverse settings. Patient Educ Couns 55:105-113. https://doi.org/10.1016/j.pec.2003.08.005

Epstein R, Street R (2011) Shared mind: communication, decision making, and autonomy in serious illness. Ann Fam Med 9:454461. https://doi.org/10.1370/afm.1301

Evans D (2003) Hierarchy of evidence: a framework for ranking evidence evaluating healthcare interventions. J Clin Nurs 12:77-84. https://doi.org/10.1046/j.1365-2702.2003.00662.x

Feldman R (2005) Respecting the evidence. Philos Perspect 19:95-119. https://doi.org/10.1111/j.1520-8583.2005.00055.x

Freeman J (2005) Systematizing Toulmin's warrants: an epistemic approach. Argumentation 19:331-346. https://doi.org/10.1007/ s10503-005-4420-0
Godden D, Walton D (2006) Argument from expert opinion as legal evidence: critical questions and admissibility criteria of expert testimony in the American legal dystem. Ratio Juris 19:261-286. https://doi.org/10.1111/j.1467-9337.2006.00331.x

Graffigna G, Barello S, Riva G et al (2017) Fertilizing a patient engagement ecosystem to innovate healthcare: toward the first Italian Consensus Conference on patient engagement. Front Psychol 8:1-6. https://doi.org/10.3389/fpsyg.2017.00812

Gupta M, Upshur R (2012) Critical thinking in clinical medicine: what is it? J Eval Clin Pract 18:938-944. https://doi.org/10.111 1/j.1365-2753.2012.01897.x

Guyatt G, Rennie D (2002) Users guides to the medical literature: a manual for evidence-based clinical practice. AMA Press, Chicago

Guyatt G, Cairns J, Churchill D et al (1992) Evidence-based medicine: a new approach to teaching the practice of medicine. JAMA 268:2420-2425. https://doi.org/10.1001/jama.1992.0349017009 2032

Heisler M, Bouknight R, Hayward R et al (2002) The relative importance of physician communication, participatory decision making, and patient understanding in diabetes self-management. J Gen Intern Med 17:243-252. https://doi.org/10.104 6/j.1525-1497.2002.10905.x

Hickey J (2016) The nature of evidence as a basis for evaluation. In: Christine B, Hickey J (eds) Evaluation of health care quality for DNPs. Springer, New York, pp 37-60

Hitchcock D (2006) Good reasoning on the Toulmin model. In: Hitchcock D, Verheij B (eds) Arguing on the Toulmin Model. Springer, Dordrecht, pp 203-218

Hitchcock D (2017) On reasoning and argument: Essays in informal logic and on critical thinking. Springer, Cham

Iordanou K, Kendeou P, Beker K (2016) Argumentative reasoning. In: Greene J, Sandoval W, Brêaten I (eds) Handbook of epistemic cognition. Routledge, New York, pp 51-65

Kelly GJ, Takao A (2002) Epistemic levels in argument: an analysis of university oceanography students' use of evidence in writing. Sci Educ 86:314-342. https://doi.org/10.1002/sce.10024

Kinneavy J (2002) Kairos in classical and modern rhetorical theory. In: Sipiora P, Baumlin J (eds) Rhetoric and kairos: Essays in history, theory, and praxis. SUNY Press, Albany, pp 58-76

Kinneavy J, Eskin C (2000) Kairos in Aristotle's rhetoric. Writ Commun 17:432-444. https://doi.org/10.1177/0741088300017003005

Kuhn D (1999) A developmental model of critical thinking. Educ Res 28:16. https://doi.org/10.2307/1177186

Kuhn D (2002) What is scientific thinking and how does it develop? In: Goswami U (ed) The Wiley-Blackwell handbook of childhood cognitive development, 2nd edn. Blackwell, Oxford, pp 497-523

Latour B (1987) Science in action: how to follow scientists and engineers through society. Harvard University Press, Cambridge

Macagno F, Bigi S (2017a) Analyzing the pragmatic structure of dialogues. Discourse Stud 19:148-168. https://doi.org/10.1177/14614 45617691702

Macagno F, Bigi S (2017b) Understanding misunderstandings. Presuppositions and presumptions in doctor-patient chronic care consultations. Intercult Pragmat 14:49-75. https://doi.org/10.1515/ ip-2017-0003

Macagno F, Bigi S (2020) Analyzing dialogue moves in chronic care communication - dialogical intentions and customization of recommendations for the assessment of medical deliberation. J Argumentation Context Advance online publication

Macagno F, Walton D (2014) Emotive language in argumentation. Cambridge University Press, New York

Macagno F, Walton D (2017) Interpreting straw man argumentation. The pragmatics of quotation and reporting. Springer, Amsterdam

Manz E, Renga IP (2017) Understanding how teachers guide evidence construction conversations. Sci Educ 101:584-615. https://doi. org/10.1002/sce. 21282 
Mayweg-Paus E, Macagno F (2016) How dialogic settings influence evidence use in adolescent students. Zeitschrift für Pädagogische Psychol 30:121-132. https://doi.org/10.1024/1010-0652/a000171

Mayweg-Paus E, Macagno F, Kuhn D (2016) Developing argumentation strategies in electronic dialogs: is modeling effective? Discourse Process 53:280-297. https://doi.org/10.1080/0163853X.2015.10403 23

McCain K (2018) Believing in accordance with the evidence. Springer, Cham

McCormack L, Thomas V, Lewis M, Rudd R (2017) Improving low health literacy and patient engagement: a social ecological approach. Patient Educ Couns 100:8-13. https://doi.org/10.1016/j. pec.2016.07.007

McNeill K, Lizotte D, Krajcik J, Marx R (2006) Supporting students' construction of scientific explanations by fading scaffolds in instructional materials. J Learn Sci 15:153-191. https://doi.org/10.1207/ s15327809j1s1502_1

Miller P, Jones-Harris A (2005) The evidence-based hierarchy: is it time for change? A suggested alternative. J Manip Physiol Ther 28:453457. https://doi.org/10.1016/j.jmpt.2005.06.010

Murad MH, Asi N, Alsawas M, Alahdab F (2016) New evidence pyramid. Evid Based Med 21:125-127. https://doi.org/10.1136/ebmed -2016-110401

Politi MC, Street R (2011) The importance of communication in collaborative decision making: facilitating shared mind and the management of uncertainty. J Eval Clin Pract 17:579-584. https://doi.org/1 0.1111/j.1365-2753.2010.01549.x

Reed C, Rowe G (2005) Translating Toulmin diagrams: theory neutrality in argument representation. Argumentation 19:267-286. https://doi. org/10.1007/s10503-005-4416-9

Roberts R, Gott R (2006) The role of evidence in the new KS4 national curriculum for England and the AQA specifications. Sch Sci Rev 87:29-39

Roberts R, Gott R (2010) Questioning the evidence for a claim in a socioscientific issue: an aspect of scientific literacy. Res Sci Technol Educ 28:203-226. https://doi.org/10.1080/02635143.2010.506413

Roberts R, Johnson P (2015) Understanding the quality of data: a concept map for 'the thinking behind the doing' in scientific practice. Curric J 26:345-369. https://doi.org/10.1080/09585176.2015.1044459

Sackett D (1989) Rules of evidence and clinical recommendations on the use of antithrombotic agents. Chest $95: 2 \mathrm{~S}-4 \mathrm{~S}$. https://doi. org/10.1378/chest.95.2_Supplement.2S
Street R, Elwyn G, Epstein R (2012) Patient preferences and healthcare outcomes: an ecological perspective. Expert Rev Pharmacoecon Outcomes Res 12:167-180. https://doi.org/10.1586/erp.12.3

Sugrue C, Joyce C, Carroll S (2019) Levels of evidence in plastic and reconstructive surgery research. Plast Reconstr Surg-Glob Open. https://doi.org/10.1097/GOX.0000000000002408

Taylor K (2009) Paternalism, participation and partnership - the evolution of patient centeredness in the consultation. Patient Educ Couns 74:150-155. https://doi.org/10.1016/j.pec.2008.08.017

Toulmin S (1958) The uses of argument. Cambridge University Press, Cambridge

Upshur R (2009) Making the grade: assuring trustworthiness in evidence. Perspect Biol Med 52:264-275. https://doi.org/10.1353/pbm.0.0079

van Dam HA, Van der Horst F, Van den Borne B et al (2003) Providerpatient interaction in diabetes care: effects on patient self-care and outcomes: a systematic review. Patient Educ Couns 51:17-28. https ://doi.org/10.1016/s0738-3991(02)00122-2

Wagner E, Austin B, Davis C et al (2001) Improving chronic illness care: translating evidence into action. Health Aff 20:64-78. https://doi. org/10.1377/hlthaff.20.6.64

Walton D (1989) Informal logic. Cambridge University Press, New York

Walton D (1990) What is reasoning? What is an argument? J Philos 87:399-419. https://doi.org/10.2307/2026735

Walton D (2002) Legal argumentation and evidence. The Pennsylvania State University Press, University Park

Walton D (2007) Witness testimony evidence. Argumentation, artificial intelligence, and law. Cambridge University Press, New York

Walton D (2016) Argument evaluation and evidence. Springer, Cham

Walton D, Krabbe E (1995) Commitment in dialogue. State University of New York Press, Albany

Walton D, Reed C (2008) Evaluating corroborative evidence. Argumentation 22:531-553. https://doi.org/10.1007/s10503-008-9104-0

Wolpert H, Anderson B (2001) Management of diabetes: are doctors framing the benefits from the wrong perspective? BMJ Br Med J 323:994-996. https://doi.org/10.1136/bmj.323.7319.994

Ziman J (1991) Reliable knowledge: an exploration of the grounds for belief in science. Cambridge University Press, Cambridge, UK

(1979) The periodic health examination. Canadian Task Force on the Periodic Health Examination. Can Med Assoc J 121:1193-1254

Publisher's Note Springer Nature remains neutral with regard to jurisdictional claims in published maps and institutional affiliations. 